\title{
Is there any superiority of the different abdominal closure techniques for primary closure in high-risk patients?
}

\author{
Mürşit Dincer, Erhan Aygen
}

Department of General Surgery, Firat University Hospital, Elaziğ, Turkey

Submitted: 30 November 2018

Accepted: 18 March 2019

Arch Med Sci Civil Dis 2019; 4: e16-e21

DOI: https://doi.org/10.5114/amscd.2019.84522

Copyright @ 2019 Termedia \& Banach

\section{Abstract}

Introduction: Incisional hernia continues to be one of the major problems of surgery due to its high incidence rate and high morbidity. The aims of this study are to compare different repair techniques with primary repair techniques for the risk of incisional hernia.

Material and methods: High-risk patients who had a midline incision of the abdomen were included in this study. Patients were divided into four groups. Each group contained 20 patients. Patients of group 1 were operated on using primary repair. In group 2 Cardiff repair technique was used. The patients in group 3 were repaired with Keel technique. The patients of group 4 were repaired with onlay technique. Patients were followed up with physical examination at 3-month periods in the first year after surgery and 6-month periods in the following two years. Incisional hernia, occurrence time and other complications were noted.

Results: Eighty patients who had high risk of incisional hernia were included in this study. $47.5 \%$ of them were female and $52.5 \%$ of them were male. The average age of patients was $59.2 \pm 12.95$. Average hospitalization time was 8.5 days (4-28 days). Average follow-up was 18 months (6-34 months). In total $4(5 \%)$ patients had recurrence. Fifteen percent of patients in group 1 had recurrence and $5 \%$ of patients in group 2 had recurrence. There was no recurrence in other groups. There was no significant difference for incisional hernia and the other complications between groups ( $p=0.368)$.

Conclusions: There was no significant difference between the techniques in terms of the development of incisional hernias or complications.

Key words: incisional hernia, abdominal surgery, repair techniques of abdominal incisions.

\section{Introduction}

Hernia that occurs after incision on the anterior wall of the abdomen is called incisional hernia. Incisional hernia causes significant losses of work productivity and reduces quality of life in daily life. Incisional hernia continues to be one of the major problems of the surgery due to its high incidence rate and high morbidity. The rates of developing incisional hernia after laparotomy range from $2 \%$ to $11 \%$ [1-3].

In general, it was shown that there is no significant difference in hernia development between interrupted or continuous suturing techniques and between mass closure or layered closure of incisions. It was reported that the closure process with continuous suture technique is complet-

\author{
Corresponding author: \\ Dr. Mürşit Dincer \\ Department \\ of General Surgery \\ Firat University \\ Hospital \\ 34100 Istanbul, Turkey \\ Phone: +90 5446422820 \\ E-mail: drmursitdincer@ \\ gmail.com
}


ed in a shorter time and the cost of the suturing material is lower and this technique does not increase the risk of incisional hernia. In addition, the continuous suture technique has the advantages of distributing the tensile strength to the entire wound margin and creating less tissue necrosis $[1,4,5]$.

In this study, the differences between the different closure techniques and the primary closure, the relationship between the time of separation of the edges of the fascia and incisional hernia, the time of hernia development of different techniques and the effects of the risk of developing hernia were investigated in the patient groups who were at high risk in terms of incisional hernia development.

\section{Material and methods}

The cases in which laparotomy was performed with a midline incision at the Firat University Hospital General Surgery Clinic between April 2008 and December 2010 and the development rate of incisional hernia was high were included in the study. The high risk identification criteria are given below:

- Advanced age (over 60 years),

- Obesity (body mass index (BMI) $\geq 30 \mathrm{~kg} / \mathrm{m}^{2}$ ),

- Patients with malignancy and/or receiving chemotherapy,

- Immunosuppressive drug use,

- Diabetic,

- Chronic obstructive pulmonary disease (COPD) diagnosis.

The age, gender, occupation, body mass index, additional systemic diseases and other existing pathologies of each patient were recorded in the special forms prepared for these patients. Biochemical, hematological and other necessary tests were routinely performed before the operations. American Society of Anesthesiologists (ASA) risk values were recorded. Patients were prepared for elective surgery. Total parenteral nutrition (TPN) was given to malnourished patients before and after surgery by evaluating nutrition levels. Routine nutrition was applied to patients in the postoperative period. A single prophylactic antibiotic was administered to all patients before surgery. A single dose of additional antibiotics was given to the patients in whom a prosthesis was used.

The selected cases were divided into 4 groups consisting of 20 people according to the techniques of closure. Non-absorbable monofilament polypropylene suture as suture material was used in all cases. The fascia of the cases in group 1 was closed as a primary. The Cardiff method was used in group 2. In group 3 cases, the Keel method was applied. The fascia of the cases in group 4 was closed by placing onlay patch on continuous sutur- ing. Patients were checked by performing physical examination at intervals of three months in the first year and intervals of 6 months in the second and third years after surgery. Incisional hernia development, its duration and other complications were recorded. The performed procedures were compared in terms of the sizes of incisions made, operation times, blood transfusions performed during and after surgery, time to remove the drain in cases of using drainage, complications during follow-up, time to remove sutures, duration of hospitalization and follow-up periods in the postoperative period.

The patients were mobilized as soon as possible after the operation. Respiratory exercises were performed in the early period. The patients were examined every day during the hospitalization. Daily wound care was performed as regular and standard, and any complications were recorded. Drain was removed when drainage was less than $20 \mathrm{ml} /$ day in patients in whom an abdominal drain was applied. In the shortest possible time, drugs were given to patients receiving oral medical treatment for additional systemic diseases. Standard antibiotherapy was not established. Patients were checked with clinical examination at every 3 months for the first year and every 6 months for the 2 years after the first year. Defect size and hernia development durations were recorded in patients with determined incisional hernia development in clinical controls.

Ethics committee approval was received for the present study from Firat University Ethics Committee.

\section{Statistical analysis}

The SPSS program was used for statistical analysis in the study. The groups were assessed by the Kolmogorov-Smirnov test for incisional hernia development, hernia defects, and performed operations, and by the Kruskal-Wallis test for age, gender, complications, incision types and sizes.

\section{Results}

Eighty patients with risk of developing incisional hernia were included in the study; 38 (47.5\%) patients were female and 42 (52.5\%) were male. The mean age was $59.2 \pm 12.95$. The youngest patient was 27 years old and the oldest patient was 86 years old. There was no significant difference between the groups in terms of age, gender, or risk distribution (Tables I and II).

In the cases, midline incisions were used (Table III). The performed procedures, shape and size of incision were recorded (Tables IV and V). There were no significant differences between groups in terms of operation time, hospital stay, and blood transfusion (Table VI). The mean duration of hos- 
Table I. Age and gender

\begin{tabular}{|lcccccc|}
\hline Parameter & $\begin{array}{c}\text { Group 1 } \\
(n=20)\end{array}$ & $\begin{array}{c}\text { Group 2 } \\
(n=20)\end{array}$ & $\begin{array}{c}\text { Group 3 } \\
(n=20)\end{array}$ & $\begin{array}{c}\text { Group 4 } \\
(n=20)\end{array}$ & Total & -value \\
\hline Age & $\begin{array}{c}56.55 \\
(27-83)\end{array}$ & $\begin{array}{c}56.85 \\
(30-76)\end{array}$ & $\begin{array}{c}65.65 \\
(39-86)\end{array}$ & $\begin{array}{c}57.75 \\
(39-75)\end{array}$ & $\begin{array}{c}59.2 \\
(27-86)\end{array}$ & $0.138^{*}$ \\
\hline $\begin{array}{l}\text { Gender: } \\
\text { Female }\end{array}$ & 7 & 11 & 8 & 12 & 38 & $0.339^{*}$ \\
\hline Male & 13 & 9 & 12 & 8 & 42 \\
\hline
\end{tabular}

*Kruskal Wallis test, $p<0.05$ values are significant.

Table II. Risk groups

\begin{tabular}{|c|c|c|c|c|c|c|c|c|c|c|}
\hline \multirow[t]{2}{*}{ Parameter } & \multicolumn{2}{|c|}{ Group 1} & \multicolumn{2}{|c|}{ Group 2} & \multicolumn{2}{|c|}{ Group 3} & \multicolumn{2}{|c|}{ Group 4} & \multicolumn{2}{|c|}{ Total } \\
\hline & $n$ & $\%$ & $n$ & $\%$ & $n$ & $\%$ & $n$ & $\%$ & $n$ & $\%$ \\
\hline Age & 10 & 50 & 9 & 45 & 15 & 75 & 9 & 45 & 43 & 53.75 \\
\hline Diabetes mellitus & 8 & 40 & 4 & 20 & 7 & 35 & 5 & 25 & 24 & 30 \\
\hline Immunosuppression & 2 & 10 & 4 & 20 & 1 & 5 & 3 & 15 & 55 & 68.75 \\
\hline COPD & 4 & 20 & 1 & 5 & 3 & 15 & 0 & 0 & 8 & 10 \\
\hline Obesity & 5 & 25 & 3 & 15 & 2 & 10 & 2 & 10 & 12 & 15 \\
\hline Gastric cancer & 7 & 35 & 6 & 30 & 6 & 30 & 9 & 45 & 28 & 35 \\
\hline Colon cancer & 4 & 20 & 6 & 30 & 7 & 35 & 4 & 20 & 21 & 26.25 \\
\hline Rectum cancer & 4 & 20 & 2 & 10 & 2 & 10 & 2 & 10 & 10 & 12.5 \\
\hline Esophagus cancer & - & - & 2 & 10 & 2 & 10 & - & - & 4 & 5 \\
\hline
\end{tabular}

Table III. Incisions

\begin{tabular}{|c|c|c|c|c|c|c|c|c|c|c|c|}
\hline \multirow[t]{2}{*}{ Parameter } & \multicolumn{2}{|c|}{ Group 1} & \multicolumn{2}{|c|}{ Group 2} & \multicolumn{2}{|c|}{ Group 3} & \multicolumn{2}{|c|}{ Group 4} & \multicolumn{2}{|c|}{ Total } & \multirow[t]{2}{*}{$P$-value } \\
\hline & $n$ & $\%$ & $n$ & $\%$ & $n$ & $\%$ & $n$ & $\%$ & $n$ & $\%$ & \\
\hline Upper median incision & 10 & 50 & 9 & 45 & 12 & 60 & 11 & 55 & 42 & 52.5 & $0.637^{*}$ \\
\hline Lower median incision & 8 & 40 & 8 & 40 & 8 & 40 & 7 & 35 & 31 & 38.75 & \\
\hline $\begin{array}{l}\text { Upper + lower median } \\
\text { incision }\end{array}$ & 2 & 10 & 3 & 15 & 0 & 0 & 2 & 10 & 7 & 8.75 & \\
\hline
\end{tabular}

${ }^{*}$ Kruskal-Wallis test, $p<0.05$ values are significant.

Table IV. Incision lengths

\begin{tabular}{|lccccc|}
\hline Parameter & Group 1 & Group 2 & Group 3 & Group 4 & P-value \\
\hline $\begin{array}{l}\text { Average incision } \\
\text { lengths }[\mathrm{cm}]\end{array}$ & $13.3(10-22)$ & $12(8-15)$ & $12.8(10-15)$ & $13.4(10-25)$ & $0.660^{*}$ \\
\hline
\end{tabular}

${ }^{*}$ Kruskal Wallis test, $p<0.05$ values are significant.

pitalization was 8.5 days (4-28 days). The mean follow-up period was 18 months (6-34 months).

In follow-ups, incisional hernia developed in a total of 4 cases (5\%). The developmental rate of incisional hernia in group 1 was $15 \%$ and in group 2 it was 5\%. No incisional hernia developed in the other groups. There was no statistically significant difference between groups in terms of incisional hernia development ( $p=0.368)$.

All cases with hernia development contained more than one risk factor. All the patients had ma- lignancy. The largest defect size in the cases was measured as $15 \times 10 \mathrm{~cm}$ (Table VII). There was no significant difference between the incision size and the development of incisional hernia.

In the early period, wound-site complications such as hematoma, seroma and infection developed in 12 (15\%) cases. Incisional hernia developed due to wound infection in 3 of the cases with complications. Most of the wound complications were seen in the group in which primary repair was applied (Table VIII). The patient with 
Table V. Surgical procedures

\begin{tabular}{|c|c|c|c|c|c|}
\hline Procedure & Group 1 & Group 2 & Group 3 & Group 4 & Total \\
\hline Colectomy & 4 & 6 & 5 & 5 & 20 \\
\hline Gastrectomy & 7 & 6 & 4 & 6 & 23 \\
\hline Low anterior resection & 4 & 2 & 1 & 2 & 9 \\
\hline Partial small bowel resection & 2 & - & - & 1 & 3 \\
\hline Sigmoid resection & 1 & 1 & 2 & 1 & 5 \\
\hline Intra-abdominal biopsy & 2 & 1 & 4 & 3 & 10 \\
\hline Esophagectomy & - & 2 & 1 & - & 3 \\
\hline Splenectomy & - & 1 & - & - & 1 \\
\hline Intra-abdominal mass excision & - & 1 & 3 & - & 4 \\
\hline Gastrojejunostomy & - & - & - & 2 & 2 \\
\hline
\end{tabular}

Table VI. Follow-ups

\begin{tabular}{|lcccc|}
\hline Parameter & Group 1 & Group 2 & Group 3 & Group 4 \\
\hline Operation times [h] & $3.3(1.5-6)$ & $2.6(1-5.5)$ & $3.4(1-6)$ & $3.7(2-5.5)$ \\
\hline Hospital stay [days] & $8.8(4-24)$ & $7.8(4-15)$ & $8.2(5-17)$ & $9.2(7-19)$ \\
\hline Blood transfusion $(n / \%)$ & $13 / 65$ & $8 / 40$ & $9 / 45$ & $9 / 45$ \\
\hline
\end{tabular}

Table VII. Incisional hernia development duration and defect size

\begin{tabular}{|lcccc|}
\hline Parameter & Patient 1 & Patient 2 & Patient 3 & Patient 4 \\
\hline Group & 1 & 1 & 1 & 2 \\
\hline Hernia development periods & 3 month & 1 month & 12 day & 1 year \\
\hline Defect size & $15 \times 10 \mathrm{~cm}$ & $8 \times 5 \mathrm{~cm}$ & $7 \times 4 \mathrm{~cm}$ & $12 \times 10 \mathrm{~cm}$ \\
\hline
\end{tabular}

Table VIII. Complications

\begin{tabular}{|c|c|c|c|c|c|}
\hline Complication & Group 1 & Group 2 & Group 3 & Group 4 & $P$-value \\
\hline Wound infection & 4 & 3 & - & 5 & $0.143^{*}$ \\
\hline Wound disintegration & 2 & 3 & 1 & 3 & $0.715^{*}$ \\
\hline Wound abscess & - & 4 & 2 & - & $0.05^{\star}$ \\
\hline $\begin{array}{l}\text { Intra-abdominal } \\
\text { abscess }\end{array}$ & - & - & 1 & - & \\
\hline Cough & - & - & 1 & - & \\
\hline Tachycardia & 1 & - & - & - & \\
\hline Pneumonia & - & - & - & 1 & \\
\hline Seroma & - & - & - & 3 & \\
\hline Hematoma & - & - & - & 2 & \\
\hline Rectovaginal fistula & 1 & - & - & - & \\
\hline Atelectasis & - & 2 & - & 1 & \\
\hline
\end{tabular}

${ }^{*}$ Kruskal-Wallis test, $p<0.05$ values are significant. 
rectovaginal fistula complication was treated conservatively. In the group in which a prosthesis was used, seroma in 3 cases and hematoma in 2 cases developed. These complications were treated with daily aspirations. In group 3, an intra-abdominal abscess developed in one case and image-guided drainage was performed.

As a result of this study, there was no statistically significant difference between these techniques in terms of the incisional hernia development and the complications ( $p=0.368)$. There was no statistical significance in terms of risk factors investigated and incisional hernia development.

\section{Discussion}

Incisional hernia is one of the most common problems after surgical procedures performed on the abdomen. It is accepted that the reported incidence of incisional hernia is between $2 \%$ and $11 \%$ and shows variability. Incisional hernia causes significant losses of work productivity and reduces the quality of life in daily life. Incisional hernia continues to be one of the major problems of the surgery due to its high incidence rate and high morbidity $[2,6,7]$. In the development of incisional hernia, it may not be possible to change uncontrollable factors related to the patient (age, sex, additional disease, general body weakness). However, the controllable factors (obesity, incision shape, surgical technique, contamination, suture material) may be minimized by the right choice and proper practice [8]. Incisional hernia is not only specific to elderly illness, but wound healing is impaired in patients over 60 years of age. The presence of systemic sepsis and negative nitrogen balance during primary surgery causes poor tissue healing. For this reason, sepsis should definitely be treated before elective surgery. In patients with carcinoma, cirrhosis, hypoalbuminemia, vitamin deficiency, uremia, jaundice, and transplantation, the immunosuppression causes general body weakness and poses a high risk for incisional hernia. In the postoperative period, pulmonary complications increase the tension in the wound by causing coughing and thus increase the incidence of hernia development. It was detected that the chronic use of immunosuppressive agents is detrimental to primary wound healing [9].

In most of the etiologic factors, the problem is that excessive tension develops in the incision and the wound healing is bad [10, 11]. Incision shape is one of the most important factors of wound healing and is under the surgeon's control. Transverse incisions heal better than vertical in cisions and cause less herniation [10]. Likewise, careful closure of the incision also affects wound healing. If the sutures are placed at a distance of $1 \mathrm{~cm}$ or less from the edge of the fascia, the sutures can cut the fascia edge. Therefore, when a vertical incision is used, the sutures should be placed at least $2 \mathrm{~cm}$ from the edge of the fascia $[12,13]$.

In a study of excessive tension and tissue resistance, Douglas reported that wounded aponeurotic tissue reached $20 \%$ of the original resistance 4 months after injury, and $80 \%$ of the original resistance 8 months after [14]. This study shows that it is necessary to use late-absorbable suture material in the closure of abdominal incisions. For this reason, an absorbable stitch must provide resistance for at least 8 weeks to avoid risk of wound dehiscence. The $2.7 \mathrm{~kg}$ breaking resistance is protected by catgut for 3 weeks, vicryl suture for 4 weeks, and PDS suture for 8 weeks. PDS is a biosynthetic absorbable material with 1.7 times higher tension resistance when applied as a monofilament with the same diameter, and it protects $50 \%$ of the power for 5 weeks. The incidence of incisional hernia was thought to be higher in absorbable suture materials than non-absorbable suture materials. However, in studies it was shown that there was no significant difference between late-absorbable suture materials such as PDS, and non-absorbable suture materials in terms of incisional hernia development $[11,12,15]$.

In a study conducted at the Toronto Shouldice Clinic, it was reported that $5.6 \%$ of incisional hernias occurred in the first 2 weeks, $52 \%$ in the first 6 months, $67 \%$ in the first year, $78 \%$ in the first 2 years and $88 \%$ in the first 4 years [16]. In our study, incisional hernia developed in four of all cases, and incisional hernias in all of these four cases developed in the first year. Incisional hernia occurred in the first case in the first 2 weeks, in the second case at the end of the first month, in the third case in the third month, and in the last case at the end of the first year.

Various modifications of the primary closure were on trial to prevent the development of incisional hernia. In an experimental study conducted by Meeks et al., the primary repair and Cardiff technique were compared; it was found that the Cardiff technique took a longer time but was statistically significantly more effective [17].

In primary repair, recurrence rates are high because of tension caused by sutures in the incision area [18]. The number of procedures performed with prosthetic materials increased rapidly after the description of tension-free surgery by Lichtenstein et al. Concordantly, the recurrence rate also fell below 20\% [19]. In another study conducted in patients at risk in terms of wound healing, it was shown that the application of onlay patch after primary closure of laparotomies reduces the rate of incisional hernia development [20].

In this study, abdominal wall incisions were repaired with different primary repair modifications and onlay patch method, and the superiority of 
these techniques to each other was compared in the postoperative period in terms of incisional herniation and complications. Incisional hernia developed at a rate of $15 \%$ in the primary repair group and $5 \%$ in the group repaired with the Cardiff technique. Incisional hernia did not develop in the group treated with the Keel technique or in the group repaired with the onlay patch. It was detected that there was no statistically significant difference between the groups in terms of hernia development. It was found that the incisional hernia occurred more often in cases where wound complications developed.

In the literature, it was reported that rates of wound complications such as hematoma, seroma or infection after incision repair were in the range $0-36 \%[21,22]$. When wound infection alone is considered, it increases the risk of developing hernia 4-fold [23]. In this study, such complications developed in $15 \%$ of cases (12 cases). Incisional hernia developed due to wound infection in three of the cases with complications. When all cases were compared, the rate of hernia development was $3.75 \%$, whereas it was $25 \%$ among patients with complications. Most of the wound complications were observed in the primary repair group but no marked and significant difference was found between the groups.

In conclusion, in this study, it was found that in cases at high risk in terms of incisional hernia development, good results can be obtained with appropriate surgical techniques both in primary repair modifications and in repair with onlay mesh. Although there is no statistical difference between the techniques in terms of incisional hernia development and complications, studies with larger numbers of cases and longer follow-up times will be appropriate in terms of confirmation of the results.

\section{Conflict of interest}

The authors declare no conflict of interest.

\section{References}

1. Santora TA, Rosalyn J. Incisional hernia. Surg Clin N Am 1993; 73: 557-70

2. Mudge M, Hughes LE. Incisional hernia: a ten year prospective study of incidence and attitudes. $\mathrm{Br} J$ Surg 1985; 72: 70-1.

3. Regnard JF, Hay JM, Rea S. Ventral incisional hernias: incidence, date of recurrence, localization and risk factors. Ital J Surg Sci 1988; 3: 259-65.

4. Gislason H, Gronbech JE, Soreide O. Burst abdomen and incisional hernia after major gastrointestinal operations - comparison of three closure techniques. Eur J Surg 1995; 161: 354-94.

5. Wissing J, Van Vroonhoven TJ, Schttenkerk ME, Veen HF, Ponsen RJ, Jeekel J. Fascia closure after midline laparotomy: results of a randomized trial. Br J Surg 1987; 74: 738-41.
6. Schoetz DJ, Çöller JA, Veidenheimer MC. Closure of abdominal wounds with polydioxanone: a prospective study. Arch Surg 1988; 123: 72-4.

7. Larson GM, Vantertoll DJ. Approaches to repair of ventral hernia and full thickness loses of the abdominal wall. Surg Clin North Am 1984; 64: 335-49.

8. Chouillard EY, Aura T, Picone O, Etienne JC, Fingerhut A. Incisional hernias I. related risk factors. Dig Surg 2003; 20: 3-9.

9. Ferahköşe Z, Menteş BB. Karın duvarı hernileri. Engin A (editör). Genel Cerrahi Tanı ve Tedavi ilkeleri 1.Baskı, Ankara: Atlas Yayıncilık 2000: 419-20.

10. Poole GV. Mechanical factors in abdominal wound closure: the prevention of fascail dehiscence. Surgery 1985; 97: 631-40.

11. Bucknall TE, Cox PJ, Ellis H. Burst abdomen and incisional hernia: a prospective study of 1129 major laparatomies. $\mathrm{Br}$ Med J 1982; 284: 931-3.

12. Carlson MA, Ludvig KA, Condon RE. Ventral hernia and other complications of 1000 midline incisions. South Med J 1995; 88: 450-3.

13. Stoppa RE. The treatment of complicated groin and incisional hernias. World J Surg 1989; 13: 545-54.

14. Trostle SS, Hendrickson DA. Suture sinus formation following closure of ventral midline incisions with polyproIplylene in three horse. J Am Vet Med Assoc 1995; 207: 742-5.

15. Sahlin S, Ahlberg J, Granström L, Ljungstrom KG. Monofilament versus multifilament absorbable sutures for abdominal closure. Br J Surg 1993; 80: 322-4.

16. Shukla VK, Mongha R, Gupta N, Chauhan VS. Incisional hernia comparison of mesh repair with cardiff repair. Hernia 2005; 9: 238-41.

17. Meeks GR, Nelson KC, Byars RW. Wound strength in abdominal incisions: a comparison of two continuous mass closure techniques in rats. Am J Obstet Gynecol 1995; 173: 1676-83.

18. Sheen AJ. Prosthetics in hernia repair. Surg Today 2005; 35: 196-8.

19. Lichtenstein IL, Shulman AG, Amid PK, Montllor MM. The tension free hernioplasty. Am J Surg 1989; 157: 188-93.

20. De la pena CG, Achirica CM, Dominguez-Adame E, Achirica JM. Primary closure of laparotomies with high risk of incisional hernia using prosthetic material: analysis of usefulness. Hernia 2003; 7: 134-6.

21. Trupka AW, Hallfeldt KK, Schmidbauer S, Schweiberer L. Management of complicated incisional hernias with underlay technique implanted polypropylene mesh. An effective technique in French hernia surgery. Chirurg 1999; 70: 217.

22. Schumpelick V, Conze J, Klinge U. Preperitoneal meshplasty in incisional hernia repair. A comparative retrospective study of 272 operated incisional hernias. Chirurg 1996; 67: 1028-35.

23. Cherry GW, Hughes MA, Kingnort AN, Arnold FW. Wound healing. In: Oxford Textbook of Surgery, Morris PJ, Malt RA (eds). Oxford Publishing, London 1994; 3-23. 